\title{
PERAWATAN DIRI LANSIA HIPERTENSI DI KELURAHAN CIREJAG KARAWANG
}

\author{
Irma Darmawati $^{1}$, Doni Dulgani ${ }^{2}$ \\ Sekolah Tinggi Ilmu Keperawatan PPNI Jawa Barat ${ }^{1,2}$ \\ Email: irma_darmawati87@yahoo.com
}

\begin{abstract}
ABSTRAK
Pendahuluan: Hipertensi merupakan penyakit dengan prevalensi yang tinggi pada kelompok lansia. tanda dan gelaja yang muncul akibat hipertensi mengakibatkan perubahan pada pemenuhan perawatan diri lansia. Perawatan diri lansia hipertensi meliputi upaya pengukuran tekanan darah secara teratur, minum obat secara teratur, berolahraga, mandi, mencuci tangan, menggunting kuku, menyikat gigi, keramas, serta mengurangi konsumsi garam. Metode: Penelitian ini menggunakan desain penelitian deskriptif kuantitatif dengan jumlah sample 95 orang, menggunakan teknik probability sampling dengan metode simple random sampling. Hasil: setengahnya responden $(53,3 \%)$ memiliki perawatan diri yang baik. dengan indikator perawatan diri tertinggi pada poin kebersihan diri sebesar $98.8 \%$ (keramas, dan sikat gigi), namun paling rendah pada kebiasaan minum obat hipertensi dan kebiasaan makan rendah garam (57\%). Diskusi: Hasil yang rendah dalam upaya perawatan inti pada lansia hipertensi terkait minum obat hipertensi dan pola makan rendah garam menunjukan masih kurangnya pengelolaan diri lansia dalam melaksanakan pengendalian hipertensi yang berakibat pada komplikasi penyakit lainnya. Saran : peneliti merekomendasikan pihak puskesmas untuk lebih aktif dalam upaya pelaksanaan program pengendalian hipertensi melalui pendekatan GERMAS dan CERDIK yang digalakan oleh kementrian kesehatan Republik Indonesia.
\end{abstract}

Kata kunci: Hipertensi, Lansia, Perawatan-Diri.

\begin{abstract}
Background: Hypertension is a disease with a high prevalence in the elderly group. signs and symptoms arising from hypertension result in changes in the fulfillment of elderly selfcare. Hypertensive elderly self care includes efforts to measure blood pressure regularly, take medication regularly, exercise, shower, wash hands, cut nails, brush teeth, wash, and reduce salt consumption. Methods: This study used a quantitative descriptive research design with 95 people as sample, using probability sampling techniques with the simple random sampling method. Results: half of the respondents (53.3\%) had good self-care. with the highest self-care indicators at the point of personal hygiene of $98.8 \%$ (shampooing and toothbrushes), but the lowest was in the habit of taking hypertension medication and low salt eating habits (57\%). Discussion: Low results in core treatment for hypertension in medication and low salt eating habits shows that there is still a lack of self-management in elderly for hypertension control which can triggers other diseases. Suggestion: researchers recommend the puskesmas to be more active in efforts to implement a hypertension control program through the GERMAS and CERDIK approaches that are promoted by the Indonesian Ministry of Health.
\end{abstract}

Keywords: Hypertension, Elderly, Self-Care. 



\section{PENDAHULUAN}

Lanjut usia (lansia) adalah pria dan wanita yang telah mencapai usia 60 tahun atau lebih, lansia sendiri merupakan proses menyeluruh yang terjadi pada saat ketika seseorang lahir ke dunia. Menurut World Health Organization (WHO) pada tahun 2013 proporsi dan populasi penduduk berusia lebih dari 60 tahun adalah $11,7 \%$ dari total populasi dunia dan diperkirakan jumlah tersebut akan terus meningkat seiring dengan peningkatan usia harapan hidup. Jumlah proporsi lansia di Indonesia juga bertambah setiap tahunya, data pada tahun 2009 menunjukan lansia berjumlah 7,49\% dari total populasi, tahun 2011 menjadi 7,69\% dan pada tahun 2013 didapatkan proporsi lansia sebesar $8,1 \%$ dari total populasi (WHO,2015).

Jumlah penduduk lansia di Indonesia tahun 2006 sebesar kurang lebih 19 juta lansia dengan usia harapan hidup 66 tahun, pada tahun 2020 diperkirakan sebesar 28,8 juta $(11,34 \%)$ dengan usia harapan hidup 71 tahun. Peningkatahn usia harapan hidup (UHH) setiap tahunya menimbulkan risiko terjadi penyakit stroke dan jantung. Permasalahan penyakit hipertensi diberbagai aspek kehidupan lansia, baik secara individu maupun dalam kaitannya dengan keluarga dan masyarakat (Wulandahani, 2014).

Prevalensi hipertensi di Indonesia sebesar $26,5 \%$ pada taun 2013 , tetapi yang terdiagnosis oleh tenaga kesehatan riwayat minum obat hanya sebesar $9,5 \%$. Adapun yang menandakan bahwa sebagian besar kasus hipertensi di masyarakat belum terdiagnosis dan terjangkau pelayanan kesehatan (Kemenkes RI, 2013). Data kesehatan Indonesia tahun 2011 menyebutkan bahwa hipertensi merupakan salah satu dari 10 penyakit dengan kasus rawat inap terbanyak di rumah sakit pada tahun 2010, dengan proporsi kasus $42,38 \%$ pria dan $57,63 \%$ wanita, serta $4,8 \%$ pasien meninggal dunia (Kemenkes RI, 2012).

Dinas Kesehatan Provinsi Jawa Barat menyebutkan bahwa prevalensi hipertensi di Jawa Barat mencapai 29,4\%. Hipertensi bisa menyebabkan berbagai komplikasi terhadap beberapa penyakit lain, bahkan penyebab risiko terjadinya penyakit jantung, stroke, dan ginjal (Riskesdas Jabar, 2103). Hasil studi pendahuluan yang dilakukan oleh peneliti kepada Dinas Kesehatan Kabupaten Karawang dari hasil studi dokumentasi, didapatkan data pada tahun 2016 bahwa jumlah penderita hipertensi di 50 Puskesmas Kabupaten Karawang pada tahun 2016 sebanyak 14,236 orang dan kasus terbanyak terdapat di Puskesmas Jatisari berjumlah 784 orang (Dinkes Kabupaten Karawang, 2016).

Menurut Aan (2013) faktor-faktor yang dapat mempengaruhi perawatan diri lansia dalam mengontrol tekanan darah dengan cara minum obat secara teratur, mengukur tekanan darah secara teratur, meningkatkan aktivitas fisik misalnya berjalan, mengurangi konsumsi garam yang berlebih, dan diet asupan kalsium dan kalium. Perawatan diri diharapkan dilakukan agar mencegah terjadinya komplikasi.

\section{METODE}

Penelitian ini menggunakan metode penelitian survey deskriftif dengan pendekatan 
Cross sectional. Penelitian dilakukan di Kelurahan Cirejag Wilayah Kerja Puskesmas Jatisari Kabupaten Karawang. Penelitian dilakukan pada 17 Juli sampai 19 Juli 2017 dan setelah mendapatkan ijin dari pihak-pihak yang bersangkutan. Populasi adalah keseluruhan subjek penelitian. Apabila seseorang ingin meneliti semua elemen yang ada dalam wilayah penelitian, maka penelitiannya merupakan penelitian populasi. Studi atau penelitiannya juga disebut studi populasi atau studi sensus (Arikunto, 2013). Populasi dalam penelitian ini adalah sebanyak 784 lansia di Kelurahan Cirejag Wilayah Kerja Puskesmas Jatisari Kabupaten Karawang. Sampel pada penelitian ini menggunakan teknik probability sampling, secara professional (Sugiyono, 2013).

\section{HASIL}

Berdasarkan tabel 1 diperoleh hasil bahwa lebih dari setengahnya sebanyak 52 orang $(60,5 \%)$ berjenis kelamin perempuan.

Tabel 1. Distribusi Frekuensi Jenis Kelamin Responden $(\mathrm{n}=86)$

\begin{tabular}{lll}
\hline Jenis kelamin & Frekuensi & Presentase (\%) \\
\hline Laki-laki & 34 & $39,5 \%$ \\
\hline Perempuan & 52 & $60,5 \%$ \\
\hline Total & 86 & $100 \%$ \\
\hline
\end{tabular}

Berdasarkan tabel 2 diperoleh hasil bahwa lebih dari setengah responden 51 orang $(9,3 \%)$ yang berusia 60-74 tahun.

Tabel 2. Distribusi Berdasarkan Usia Responden ( $\mathrm{n}=86)$

\begin{tabular}{ccc}
\hline Usia & Frekuensi & Presentase (\%) \\
\hline $45-59$ & 12 & $14 \%$ \\
\hline $60-74$ & 51 & $59,3 \%$ \\
\hline $75-90$ & 23 & $26,7 \%$ \\
\hline Total & 86 & $100 \%$ \\
\hline
\end{tabular}

Berdasarkan tabel 3 diperoleh hasil bahwa sebagian besar dari responden 76 orang (
88,4\%) yang berpendidikan SD (Sekolah Dasar).

Tabel 3. Distribusi Responden Berdasarkan Pendidikan. $(\mathrm{n}=86)$

\begin{tabular}{ccc}
\hline Pendidikan & Frekuensi & Presentase (\%) \\
\hline SD & 76 & $88,4 \%$ \\
\hline SMP & 8 & $9,3 \%$ \\
\hline SMA & 2 & $2,3 \%$ \\
\hline Total & 86 & $100 \%$ \\
\hline
\end{tabular}

\section{Gambaran Perawatan Diri Lansia Hipertensi}

Berdasarkan tabel 4 Diperoleh hasil bahwa lebih dari setengahnya sebanyak 46 orang $(53,5 \%)$ memiliki perawatan diri yang baik.

Tabel 4. Distribusi frekuensi perawatan diri lansia $(n=86)$

\begin{tabular}{ccc}
\hline Pendidikan & Frekuensi & Presentase (\%) \\
\hline Baik & 46 & $53,5 \%$ \\
\hline Kurang & 40 & $46,5 \%$ \\
\hline Total & 86 & $100 \%$ \\
\hline
\end{tabular}

Hasil selanjutnya diperoleh hasil bahwa lebih dari setengahnya lansia memiliki intensitas mandi yang baik sebanyak 72 orang $(83,7 \%)$, sebagian besar lansia melakukan cuci tangan dengan baik sebanyak 86 orang (100\%), sebagian besar lansia melakukan gunting kuku selama 1 minggu sekali sebanyak 83 orang $(96,5 \%)$, sebagian besar lansia yang melakukan sikat gigi setiap hari sebanyak 84 orang $(97,7 \%)$, sebagian besar lansia melakukan keramas selama 3 hari sebanyak 85 orang $(98,8 \%)$, lebih dari setengahnya lansia yang meminum obat hipertensi sebanyak 54 orang $(62,8 \%)$, sebagian besar lansia melakukan pemeriksaan tekanan darah selama 1 bulan sekali secara rutin sebanyak 75 orang $(87,2 \%)$, sebagian besar lansia melakukan olah raga ringan secara rutin sebanyak 82 orang $(95,3 \%)$, dan hampir setenganya lansia masih konsumsi garam setiap hari sebanyak 49 orang (57.0\%). 
Tabel. 5. Distribusi Frekuensi Berdasarkan Indikator Perawatan Diri

\begin{tabular}{ccccc}
\hline Indikator & \multicolumn{1}{c}{ Baik } & \multicolumn{3}{c}{ Kurang } \\
\cline { 2 - 5 } & $\mathrm{f}$ & $\%$ & $\mathrm{f}$ & $\%$ \\
\hline Intensitas mandi & 72 & $83,7 \%$ & 14 & $16,3 \%$ \\
\hline Mencuci tangan & 86 & $100 \%$ & 0 & $0 \%$ \\
\hline $\begin{array}{c}\text { Menggunting } \\
\text { kuku }\end{array}$ & 83 & $96,5 \%$ & 3 & $3,5 \%$ \\
\hline Sikat gigi & 84 & $97,7 \%$ & 2 & $2,3 \%$ \\
\hline Keramas & 85 & $98,8 \%$ & 1 & $1,2 \%$ \\
\hline $\begin{array}{c}\text { Minum obat } \\
\text { hipertensi }\end{array}$ & 54 & $62,8 \%$ & 32 & $37,2 \%$ \\
\hline $\begin{array}{c}\text { Memeriksakan } \\
\text { tekana darah }\end{array}$ & 75 & $87,2 \%$ & 11 & $12,8 \%$ \\
\hline Berolah raga & 82 & $95,3 \%$ & 4 & $4,7 \%$ \\
\hline $\begin{array}{c}\text { Mengurangi } \\
\text { konsumsi garam }\end{array}$ & 49 & $57,0 \%$ & 37 & $43,0 \%$ \\
\hline
\end{tabular}

\section{PEMBAHASAN}

Dari hasil penelitian ini mengenai gambaran perawatan diri lansia hipertensi di kelurahan cirejag wilayah kerja Puskesmas Jatisari Kabupaten Karawang menujukan bahwa distribusi frekuensi berdasarkan jenis kelamin laki-laki 34 responden $(39,5 \%)$, dan jenis kelamin perempuan 52 responden $(60,5 \%)$. Lansia laki-laki cenderung dalam status kawin sampai mereka sangat tua dan meninggal. Lansia laki-laki cenderung untuk mendapatkan bantuan/perawatan dari istri mereka, sedangkan lansia perempuan seringkali tidak mendapatkan ini karena kematian suami. Namun pada umumnya lansia perempuan yang ditinggalkan suami, hidup bersama dengan anaknya terutama anak perempuan, sehingga masih mendapatkan perawatan yang cukup baik. Oleh sebab itu dengan adanya perawatan yang lebih baik, maka harapan hidup lansia perempuan lebih panjang dari pada lansia laki-laki.

Dari hasil penelitian ini mengenai gambaran perawatan diri lansia hipertensi di kelurahan cirejag wilayah kerja Puskesmas Jatisari Kabupaten Karawang menunjukan bahwa sebagian besar berumur 60-74 responden (59,3\%). Proses menua (aging process) adalah proses alami yang disertai adanya penurunan kondisi fisik, psikologis maupun sosial yang saling berinteraksi satu sama lain. Keadaan itu cenderung berpotensi menimbulkan masalah kesehatan secara umum seperti kurangnya kemampuan responden dalam melakukan personal hygiene. Menjadi tua adalah titik balik didalam kehidupan manusia, yang ada hubungan dengan berlalunya waktu dan akhirnya akan menuju pada kematian. Sebenarnya proses kemunduran itu terjadi tidak pada satu alat saja tetapi terjadi pada seluruh tubuh. Makin panjang umur kehidupan seseorang berarti makin lama dia meninggal, maka semua bagian tubuh akan mengalami kemunduran, kekuatan berkurang, daya tahan berkurang, sehingga lansia lebih besar kemungkinan jatuh sakit.

Dapat disimpulkan bahwa semakin lanjut usia seseorang, maka akan mengalami kemunduran terutama di bidang kemampuan fisik, yang dapat mengakibatkan penurunan peranan-peranan sosialnya. Hal ini mengakibatkan timbulnya gangguan di dalam mencukupi kebutuhan hidupnya. Sehingga dapat meningkatkan bantuan orang lain. Seiring dengan bertambahnya usia populasi kita, perawat perlu untuk memeriksa kebutuhan lansia, untuk mempengaruhi kebijakan kesehatan dan untuk mengevaluasi standar praktik keperawatan gerontik, dan untuk membuat perencanaan di masa yang akan datang.

Proses penuaan merupakan suatu hal yang tidak dapat dihindarkan, akan tetapi hal tersebut dapat dipertahankan tergantung bagaimana keyakinan yang dimilliki oleh 
lansia. Passer dan Smith (2009) dalam Mustikawati, dkk (2016) berpendapat bahwa keyakinan merupakan kunci penting dimana lansia yakin terhadap kemampuannya dalam melakukan suatu perilaku untuk mencapai suatu tujuan yang diinginkan, dalam hal ini kemampuan dalam perawatan diri. Lansia yang memiliki keyakinan yang tinggi akan cenderung memiliki kemampuan dan keinginan dalam mencapai suatu tujuan.

Dari hasil penelitian ini mengenai gambaran perawatan diri lansia hipertensi di kelurahan cirejag wilayah kerja puskesmas jatisari kabupaten karawang menunjukan bahwa hampir seluruh responden berpendidkan SD 88,4\%. Pendidikan sekolah dasar yang dimasukkan dalam pendidikan dasar menjadikan pengetahuan responden masih kurang termasuk dalam pengetahuan tentang perilaku hidup bersih dan perilaku personal hygiene. Salah satu faktor yang mempengaruhi pengetahuan terhadap kesehatan adalah tingkat pendidikan (Parera 2004). Pengetahuan dapat berpengaruh terhadap sikap dan perilaku seseorang dalam masalah kesehatan (Notoatmodjo 2003). Semakin tinggi pendidikan responden, diharapkan wawasan yang dimilikinya akan semakin luas sehingga pengetahuan pun juga akan meningkat, sebaliknya rendahnya pendidikan responden, akan mempersempit wawasan sehingga akan menurunkan pengetahuan, yang berpengaruh pada perilaku perawatan kesehatan (Notoatmojo 2003).

Hasil penelitian mengenai gambaran perawatan diri lansia hipertensi di Kelurahan Cirejag Wilayah Kerja Puskesmas Jatisari Kabupaten Karawang menunjukan bahwa lebih dari setengahnya $(53,5 \%)$ memiliki perawatan diri yang baik, dimana jika dilihat berdasarkan indikator lebih dari setengahnya lansia $(83,7 \%)$ memiliki intensitas mandi yang baik, sebagian besar (100\%) lansia melakukan cuci tangan dengan baik, sebagian besar $(96,5 \%)$ lansia melakukan gunting kuku selama 1 minggu sekali, sebagian besar (97,7\%) lansia yang melakukan sikat gigi setiap hari, sebagian besar $(98,8 \%)$ lansia melakukan keramas selama 3 hari, lebih dari setengahnya $(62,8 \%)$ lansia yang meminum obat hipertensi, sebagian besar $(87,2 \%)$ lansia melakukan pemeriksaan tekanan darah selama 1 bulan sekali secara rutin, sebagian besar $(95,3 \%)$ lansia melakukan olah raga ringan secara rutin dan hampir setenganya (57.0\%) lansia masih konsumsi garam setiap hari.

Tingginya kemampuan perawatan diri pada lansia dalam hal mencuci tangan, dikarenakan mencuci tangan merupakan suatu kebiasaan hal ini dibuktikan dengan hasil penelitian bahwa seluruh lansia di Kelurahan Cirejag rutin dalam melakukan cuci tangan, dimana kebiasaan itu biasanya didasari pada suatu keyakinan. Hal ini sejalan dengan pendapat dari Lee et al (2010) dimana secara umum perawatan diri merupakan proses menjaga kesehatan melalui keyakinan positif dan pengelolaan penyakit. Individu yang mengalami penyakit kronis, dapat melakukan manajemen diri melalui perawatan diri dalam mempertahankan kesehatan serta mengurangi efek dari penyakit dan membatasi perkembangan penyakit. Hal inilah yang membuat peneliti berasumsi bahwa yang menyebabkan hasil penelitian pada indikator mencuci tangan pada lansia sebesar 100\%, karena lansia meyakini jika mencuci tangan dapat mempengaruhi kesehatan mereka dan mencegah terjadinya penyakit.

Pemenuhan kebutuhan lansia menggambarkan bagaimana lansia menjalani kehidupannya di usia senja dengan optimal. Pemenuhan kebutuhan perawatan yang cukup disebabkan karena peran keluarga masing- 
masing lansia tidak terlalu optimal. Perawatan diri merupakan suatu aktivitas yang dilakukan oleh individu untuk menjaga kesehatannya secara mandiri. Kemampuan lansia dalam memenuhi perawatan diri dipengaruhi oleh faktor internal dan eksternal. Secara internal perawatan diri dapat dipengaruhi oleh individu, sementara faktor eksternal dipengaruhi oleh lingkungan (Orem dalam Prasetyo, 2012). Perawatan diri juga bertujuan untuk meningkatkan derajat kesehatan seseorang, memelihara kebersihan diri, memperbaiki personal hygiene yang kurang, pencegahan penyakit, meningkatkan percaya diri, dan menciptakan keindahan (Tarwoto \& Wartonah, 2003).

Perawatan diri yang baik akan berpengaruh terhadap peningkatan citra tubuh individu. Citra tubuh dapat berubah, karena operasi, pembedahan atau penyakit fisik maka perawat harus membuat suatu usaha ekstra untuk meningkatkan perawatan diri dimana citra tubuh mempengaruhi cara mempertahankan kebersihan (Potter \& Perry, 2009). Body image seseorang berpengaruhi dalam pemenuhan perawatan diri karena adanya perubahan fisik sehingga individu tidak peduli terhadap kebersihannya (Tarwoto, 2011).

Pada penelitian ini diperoleh hasil dimana hampir setengahnya $57,0 \%$ lansia masih konsumsi garam setiap hari. Hal ini dikarenakan garam atau natrium memiliki dampak positif dan dampak negatif yang diketahui oleh lansia sehingga masih banyak juga lansia yang belum bisa mengurangi konsumsi garam setiap harinya. Dari sisi positif natrium membantu otot dan saraf bekerja sebagaimana mestinya dengan cara membantu kontraksi otot dan tranmisi impuls saraf.
Dampak negatif dari konsumsi garam berlebih didalam menu makanan dapat menyebabkan pembuluh darah pada ginjal menyempit dan menahan aliran darah. Untuk itulah, ginjal memproduksi hormon Renin dan Angiostenin agar pembuluh darah utama mengeluarkan tekanan darah yang besar sehingga pembuluh darah pada ginjal bisa mengalirkan darah seperti biasanya. Tekanan darah yang besar dan kuat ini menyebabkan seseorang menderita hipertensi tipe sekunder, yakni hipertensi yang disebabkan oleh masalah di bagian tubuh lainnya, dalam hal ini ginjal. selain itu hipertensi dapat memicu penyakit yang memengaruhi metabolisme tubuh lainnya seperti salah satunya diabetes (Darmawati, 2015). Konsumsi garam per hari yang dianjurkan adalah sebesar 1500-2000 mg atau setara dengan satu sendok teh.

\section{Hasil penelitian Anggara} menunjukan hasil uji statistik ada hubungan yang bermakna antara asupan natrium dengan tekanan darah dengan nilai $\mathrm{p}=0,000$. Penelitian Tanjung (2009) juga mendapatkan bahwa responden yang sering mengkonsumsi makanan tinggi natrium memiliki jumlah kasus hipertensi yang lebih besar yaitu $(58,3 \%)$ dibandingkan responden yang tidak sering mengkonsumsi makanan tinggi natrium yaitu (56,1\%). Penelitian Kamso (2000) menemukan adanya hubungan yang signifikan antara asupan natrium dengan tekanan darah.

Hasil rata-rata tekanan darah yang mengalami hipertensi di Kelurahan Cirejag Wilayah Kerja Puskesmas Jatisari Kabupaten Karawang yaitu sebesar 150/90 mmHg lansia yang mengalami hipertensi.

\section{KESIMPULAN}

a. Lebih dari setengahnya sebanyak $(60,5 \%)$ berjenis kelamin perempuan, lebih dari 
setengahnya sebanyak $(59,3 \%)$ yang berusia 60-74 tahu, lebih dari sebagian besar sebanyak $(88,4 \%) \quad$ yang berpendidikan SD.

b. Lebih dari setengahnya sebanyak 46 orang 53,5\% dalam kategori perawatan diri yang baik., sebagian besar lansia melakukan cuci tangan dengan baik (100\%), dan hampir setenganya lansia masih konsumsi garam setiap hari (57.0\%).

\section{SARAN}

Hasil penelitian ini dapat digunakan pelayanan kesehatan dalam meningkatkan pendidikan kesehatan kepada lansia, sebagaimana lansia rentan dengan penyakit hipertensi khusus nya meningkatan rutinitas dalam perawatan diri. Penkes konsumsi garam melalui kegiatan, posbindu.

\section{REFERENSI}

A'an Dwi Sentana (2013), Perawatan Diri Hipertensi Dalam Mengontrol Tekanan Darah. http://poltekkesmataram.ac.id/cp/wpcontent/uploads/2015/08/1. -arikelaan-dwi-sentana-perawatan-dirihipertensi.pdf di akses pada 8 Januari 2017 20:35

Arifin, M. H., Weta, I. W., \& Ratnawati, N. L. (2016). Faktor-faktor yang Berhubungan dengan Kejadian Hipertensi pada Kelompok Lanjut Usia di Wilayah Kerja Puakesmas Petang I Kabupaten badung 2016. Ejurnal Medika.

Arikunto, S. (2013). Prosedur Penelitian Suatu pendekatan praktik. Jakarta: Rineka Cipta.

Alimul, (2009). Perawatan hipertensi dalam mengontrolkan tekanan darahnya. http://id.portalgaruda.org/?ref=brows $\underline{e} \& \bmod =$ viewarticle \&article $=186703$

di akses pada 20 Maret 2017 20:00

Asmadi, (2008). Awas ! Anda Bisa Mati Cepat Akibat Hipertensi dan Diabetes. Yogyakarta : Power Books ( IHDINA).

Bangun, A. P. (2012). Sikap bijak bagi perokok: Solusi tuntas untuk mengurangi rokok dan berhenti merokok. Jakarta: Indocamp.

Darmawan dkk, (2008). Care your selft hipertensi. Cetakan 1. Jakarta: Penebar Plus.

Darmawati, I., Setiawan, A., \& Permatasari, H. (2015). Menurunkan Indeks Massa Tubuh Perempuan Dewasa dengan Kelebihan Berat Badan dan Kegemukan melalui Latihan Fisik Interval Training. Jurnal Keperawatan Indonesia, 18(2), 88-94.

Febby dkk. (2013) Faktor-Faktor Yang Berhubungan Dengan Tekanan Darah Di Puskesmas Telaga Murni, Cikarang Barat Tahun 2012 http://fmipa.umri.ac.id/wpcontent/uploads/2016/06/ELFIKAFAKTOR-2-YG-B.D-PD-TENSI.pdf

Hidayat , Aziz Alimul (2010). Kebutuhan Dasar Manusia: Aplikasi Konsep san Proses Keperawatan. Jakarta: Salemba Medika. 2009.

Intan, S (2016). Hubungan Antara Pengetahuan Mengenai Perilaku Pakai Sabun Pada Ibu-ibu Di Kampung Nelayan Muara Angke, Jakarta Utara. http://ejurnal.esaunggul.ac.id/index.ph p/Formil/article/viewFile/1399/1274. di akses pada 14:00

Kemenkes RI.(2012). Sistem Kesehatan Nasiaonal: Jakarta. 
Kemenkes RI, (2012). Laporan Hasil Riset Kesehatan Dasar Riskesdas Provinsi Sulawesi Selatan Tahun 2012, Badan Penelitian dan Pengembangan Kesehatan Jakarta.

Leya, I. (2014). Hubungan antara dukungan keluarga dan efikasi diri dengan perawatan diri lansia hipertensi di wilayah kerja puskesmas ujung berung kota bandung. http://repository.unpad.ac.id/20096/1/ Hubungan-Antara-Dukungan-

Keluarga-Dan-Efikasi-Diri.pdf di akses pada 23 Maret 201720.30

Mujahidullah, K. (2012). Buku Keperawatan Geriatrik (Merwat lansia dengan cinta dan kasih sayang). Yogyakarta: Pusataka Pelajar.

Riyanto, A. (2013). Statistik Inferensial Untuk Analisa Data Kesehatan. jakarta: Nuha Medika.

Rachmat, M. (2012). Buku Ajar Biostatistika. Jakarta: EGC.

Rusdi dan Isnawati. (2009). Awas! Anda Bisa Mati Cepat Akibat Hipertensi dan

Diabetes. Yogyakarta : Power Books ( IHDINA).

Sri, A. (2014). Hubungan dukungan keluarga dengan motivasi lansia hhipertensi dalam memeriksakan tekan darahnya. http://id.portalgaruda.org/?ref=brows e\&mod=viewarticle \&article $=186703$ di akses pada 22 Februari 2017 14:30

Setiadi. (2013). konsep dan Praktik Penulisan Riset Keperawatan. Yogyakarta: Graha Ilmu.

Silis (2011). Hubungan Tingkat Pengetahuan

Lansia Dengan Perilaku Lansia Dalam Pemenuhan Personal Hygiene Di Panti Wreda Darma Bakti Panjang Sukarata .https://publikasiilmiah.ums.ac.id/bitst ream/handle/11617/3648/SILISERDH AYANTI-
KARTINAHFixbgt.pdf? sequence $=1$ di akses pada 24 Juli 2017 22:30

Sugiyono. (2013). Metode penelitian Kuantitatif Kualitatif dan $R \& D$. Bandung: Alfabeta.

Shadine, M. (2010). Mengenal Penyakit Hipertensi, Diabetes, Stroke dan Serangan Jantung. Jakarta: Keenbooks.

Sandy (2016). Motivasi Lansia Hipertensi Menurunkan Tekanan darah Dengan Penatalaksaan Non Farmakologi. http://ejurnal.stikesbaptis.ac.id/index. php/keperawatan/article/view/133/112 di akses pada 06 Agustus 2017 20:30

Tarwoto dkk, (2010). Konsep dan Proses Keperawatan Keluarga, Sulawesi Selatan Pustaka As Salam.

Monica Saptiningsih (2015) Faktor-fakor Yang Berhubungan Dengan Perilaku Mencuci Tangan Pada Anak Sekolah Dasar Negri 03 Kertajaya Padalarang http:/lejournal.stikesborromeus.ac.id/f ile/jurnal\%205.pdf di akses pada 05 Agustus 2017 14:30

Notoatmodjo, S. (2010). Metodologi Penelitian Kesehatan. Jakarta: Rineka Cipta.

Orem dalam prasetyo. (2012). Hubungan Pengetahuan perawatan hipertensi dalam uoaya mengontrol tekanan darah. $\quad$ http://poltekkesmataram.ac.id/cp/wpcontent/uploads/2015/08/1. -arikelaan-dwi-sentana-perawatan-dirihipertensi.pdf di akses pada 8 Januari 2017 20:35

Wahjudi, N. (2012). Keperawatan Gerontik dan Geriatrik. Jakarta: EGC.

Wawan, dkk (2010). hubungan Pengetahuan Tentang Hipertensi Dengan Sikap Perawatan Hipertensi Pada Pasien Hipertensi. file:///C:/Users/acer/Downloads/111- 
403-1-PB.pdf di akses pada 12 Maret 2017 21:20

World Health Organization. (2015). Penyakit Hipertensi.

Wulandhani (2014). Hubungan Dukungan Keluarga Dengan Motivasi Lansia Hipertensi Dalam Memeriksakan Tekanan Darahnya. http://download.portalgaruda.org/ar ticle.php? article $=186703 \&$ val $=6447$ \&title $=$ Hubungan $\% 20$ dukungan $\% 20$ keluarga\%20dengan\%20motivasi\%2 Olansia\%20hipertensi\%20dalam\%20 memeriksakan\%20\%20Tekanan\%20 darahnya. diakses pada 03 agustus $201522: 30$ 